\title{
Geographical Patterns of Tuberculosis Notification Rates and Their Associations with Sociodemographic Characteristics in Communes in Phnom Penh, Cambodia
}

\author{
Ayano Miyashita1, Aya Hiraki1 ${ }^{1}$ Keiko Nakamura1 ${ }^{*}$, Takehito Takano', Kaoruko Seino1, \\ Saber Al-Sobaihi ${ }^{1}$, Ngy Mean Heng' ${ }^{2}$, Koeut Pichenda ${ }^{3}$ \\ ${ }^{1}$ Department of Global Health Entrepreneurship, Division of Public Health, Tokyo Medical and Dental University, Tokyo, Japan \\ ${ }^{2}$ Phnom Penh Municipality Health Department, Phnom Penh, Cambodia \\ ${ }^{3}$ Ministry of Public Health, National Institute for Tuberculosis and Leprosy, Phnom Penh, Cambodia \\ Email: *nakamura.ith@tmd.ac.jp
}

How to cite this paper: Miyashita, A., Hiraki, A., Nakamura, K., Takano, T., Seino, K., Al-Sobaihi, S., Heng, N.M. and Pichenda, K. (2019) Geographical Patterns of Tuberculosis Notification Rates and Their Associations with Sociodemographic Characteristics in Communes in Phnom Penh, Cambodia. Journal of Tuberculosis Research, 7, 118-129.

https://doi.org/10.4236/jtr.2019.72011

Received: April 20, 2019

Accepted: June 27, 2019

Published: June 30, 2019

Copyright $\odot 2019$ by author(s) and Scientific Research Publishing Inc. This work is licensed under the Creative Commons Attribution-NonCommercial International License (CC BY-NC 4.0). http://creativecommons.org/licenses/by-nc/4.0/ (c) (i) (8) Open Access

\begin{abstract}
Objective: To identify the patterns of tuberculosis (TB) notification rates in Phnom Penh and examine their relationships with the population density, socioeconomic, residential and occupational characteristics. Methods: The numbers of total TB and smear-positive pulmonary TB cases reported between January 1, 2010 and December 31, 2012 in Phnom Penh were counted for 76 communes in Cambodia according to TB registration records filed under the national TB programme. Population, socioeconomic, residential and occupational characteristics for the communes were obtained from the 2008 General Population Census of Cambodia. The following indicators were developed for individual communes: smear-positive pulmonary TB notification rate (SPTB-NR) (per 100,000 population, in 36 months), population density $\left(\right.$ per $\mathrm{km}^{2}$ ), socioeconomic indicators, residential characteristics and occupational characteristics. Geographic patterns of these indicators and characteristics were analysed using ArcGIS. Associations between SPTB-NR and characteristics were analysed. Results: A total of $4102 \mathrm{~TB}$ cases were reported in 36 months, including 2046 SPTB cases. SPTB-NR for Phnom Penh was 135 cases per 100,000; median SPTB-NR by commune was 100 . SPTB-NR was higher in outlying areas than in city centre communes; population density was high in the centre and low in the outlying areas. SPTB-NR was associated with larger percentage of household members per room (PR: 2.81, $95 \% \mathrm{CI}: 2.68-2.93)$, percentage of population resident in the same commune $<5$ years (PR: 1.00, 95\%CI: 1.00 - 1.01) and percentage of population in 4 of 10 occupational groups, even after excluding the influence of socioeconomic
\end{abstract}


characteristics. Conclusions: The SPTB-NR in Phnom Penh did not follow the pattern of population density. Socioeconomic, residential and occupational characteristics by commune were associated with SPTB-NR. Development of prevention and control programmes by considering commune level characteristics is encouraged.

\section{Keywords}

TB Notification Rate, National Tuberculosis Programme, Census Data, Area-Based Approaches, Cambodia

\section{Introduction}

\subsection{Background of Tuberculosis in Cambodia}

Although Cambodia had one of the world's highest tuberculosis (TB) rates in the 1990s, the implementation of health system reforms and a nationwide TB programme helped the country to make significant progress in terms of $\mathrm{TB}$ control. However, Cambodia is still ranked in the top 22 High Burden Countries (HBC) list by the World Health Organisation (WHO), with an infection rate of approximately 380 per 100,000 in the population in 2015 [1]. The smear-positive pulmonary TB notification rate in Cambodia has been declining since 2010 at a rate of $2.8 \%$ per year. However, this needs to reach a decline of at least $4 \%-5 \%$ per year to achieve the 2020 milestones of the WHO End TB Strategy [2].

\subsection{TB Trends in Rapidly Developing Phnom Penh in Relation to Population Density and TB}

The official estimates of the World Bank indicated that, as the capital of Cambodia, Phnom Penh has been experiencing strong economic growth over the last two decades. Although the majority of people do not live in urban settings (78.2\%), Phnom Penh has been experiencing rapid urbanisation and more people are moving into the inner city. Economic development is expected to help to reduce the incidence rates of infectious diseases in the population as growing wealth in each household improves personal hygiene and increases medical expenses. However, rapid population growth and population mobility could introduce rapid environmental changes in the characteristics of the communes that would affect public health practices. Increased population densities and unhealthy living conditions in urban slums may increase the transmission rates of infections [3]. Migration may also increase vulnerability to TB [4]. Demographic trends may have a large impact on $\mathrm{TB}$ transmission and alter the patterns of infection in heavily affected countries.

\subsection{Area-Based Approaches to Address Occupational Risk}

Although there is currently a great deal of emphasis on area-based public health 
interventions, the degree of heterogeneity in risk of TB between areas has not been addressed in sufficient detail. The available evidence in inadequate to understand the TB risks among smaller administrative units within Cambodia. There is a systematic TB prevention and control strategy in Cambodia, so standardised protocols exist and a reporting system has been established. However, variation between communes has not been taken into account. In addition, there is increasing interest in the potential association between occupation and risk of TB. Although TB is a known occupational hazard for healthcare workers [5] [6], there is a paucity of surveillance information for different occupations in different countries. These overlooked areas may contribute to the partial effectiveness of existing TB control programmes.

\subsection{Objectives of the Study}

This study was performed to identify the geographic patterns in the smear-positive pulmonary TB notification rate in Phnom Penh, and to examine their relationships with population density as well as socioeconomic, residential and occupational characteristics.

\section{Methods}

\subsection{TB Registration Data}

A descriptive analysis was performed on SPTB cases in Cambodia using TB surveillance data obtained from a TB case register for the national TB programme between January 2010 and December 2012. A total of 5126 TB patient records filed in Phnom Penh during this time were used in this study. In Cambodia, the smallest administrative unit is a commune under a district organised by a province or the municipality. Phnom Penh, the capital of Cambodia, was comprised of 76 communes and eight districts under the municipality in 2008. In the Cambodian health system, the basic organisational and reporting unit is a district, which also serves as a basic management unit of the national TB programme. Each district provides health services through healthcare centres and referring hospitals. The TB case register consisting of individual patient records collected at the healthcare centre level. The records are regularly consolidated into the register that references all notified TB cases by commune and then entered into the national databases. The information categories include age, sex, address (including residential commune, disease category, treatment outcome and laboratory data.

\subsection{Notification Rate Calculation}

The notification rate in this study was calculated based on the WHO definition: "Number of new and relapse TB cases notified to the national health authorities during a specified period of time' over 'Total population in the specified area during the same time period [7]. The smear-positive pulmonary TB notification rate (SPTB-NR) was calculated by matching the number of smear-positive pul- 
monary TB cases reported in the study period of 36 months and population commune reported in the 2008 population census and adjusted to per 100,000 population.

\subsection{Census Data}

Data on the population density as well as socioeconomic, residential and occupational characteristics were obtained from the national population data from the 2008 General Population Census of Cambodia. According to the census, Phnom Penh has a total population of 1,327,615 and 260,468 households. A total of 250,597 households categorised as General households were used in the analysis. The census included individual information as follows: age, gender, residential commune, education, occupation and household information, such as number of family members, income and ownership of typical household facilities. The disaggregated 2008 census, which was maintained in Excel, was consolidated for further analysis and ArcGIS 10.6 was used to produce maps depicting geographical distributions of notified TB cases per 100,000 population as well as the population density and four selected indicators from the census.

\subsection{Indicators for the Analysis}

In addition to population density (per $\mathrm{km}^{2}$ ), two socioeconomic indices and two residential characteristics were used in the analysis. Low wealth index (LWI) and non-education index (NEI) were developed as socioeconomic indicators. LWI was developed by performing principle component analysis (PCA) with non-ownership of six typical facilities, i.e., radio, TV, cellphone, phone, computer, and motorcycle, by household. NEI was developed according to the percentage of population aged between 15 and 64 that had never attended school or any educational institution. Number of household members per room and percentage of population living in the same commune $<5$ years were adapted as residential characteristics.

\subsection{Statistical Analysis}

All analyses were performed using Stata ver. 15 (Stata Corp, College Station, TX, USA). Bivariate and multivariate Poisson regression analysis was performed to calculate the Poisson ratio (PR) and to examine the association between SPTB-NR and population density (per $\mathrm{km}^{2}$ ) and the socioeconomic indicators, LWI and NEI, developed based on the census information. Similarly, the analysis examined the associations between SPTB-NR and residential characteristics: number of household members per room; and percentage of population living in the same commune $<5$ years. There were 162 occupations listed in the census, which were divided into 10 occupation groups in the 2008 census. Finally, the associations of these occupation groups with SPTB-NR were also examined using three models: 1) crude; 2) crude model adjusted by wealth using LWI; and 3) crude model adjusted by education using NEI. Maps to show the distribution 
patterns of SPTB-NR and socio-demographic variables were produced by using ArcGIS 10.6.

\subsection{Ethical Considerations}

Ethical approval was obtained from the Ethics Review Committee of Tokyo Medical and Dental University (TMDU) and The National Ethical Committee for Health Research in Cambodia. The study was conducted in compliance with the protocol, which was reviewed and approved by the Ethics Committees (Receipt Number: 1615 TMDU).

\section{Results}

In Phnom Penh, a total of 4102 reports of TB cases were identified with information regarding the patients' residential commune. Among them, 2046 smearpositive cases, 991 smear-negative cases, and 1065 extra pulmonary TB cases were identified through the case registry for the national TB programme between January 2010 and December 2012. The average course of treatment was 180 days and the treatment success rate was $86.5 \%$, although there was a loss to follow-up rate of $7.8 \%$. There were 999,804 people registered and the population growth rate was 2.83 between 1998 and 2008, according to the General Population Census 2008.

Figure 1 dipicts the geographical spread of SPTB-NR. The darker coloured communes indicate those with higher NR than the paler areas. High NR was observed in outlying areas of the city during the 36 months of the study.

Figure 2 shows the areal population density $\left(\mathrm{per} \mathrm{km}^{2}\right.$ ), socioeconomic (LWI
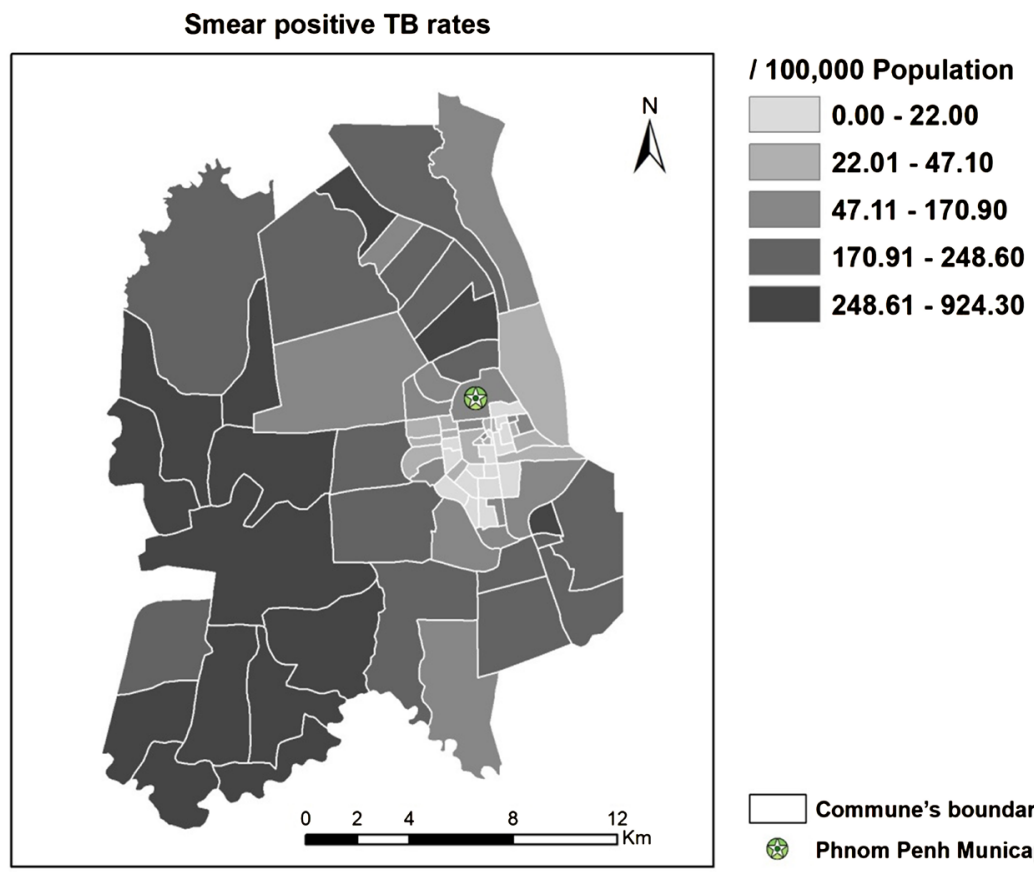

Figure 1. Smear-positive pulmonary tuberculosis notification rates (per 100,000 population) by communes in Phnom Penh, January 2010-December 2012. 


\section{Population density}

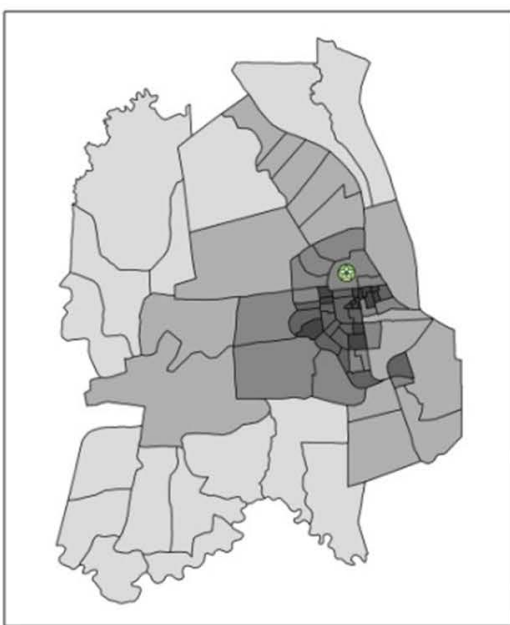

Population $/ \mathrm{Km}^{2}$

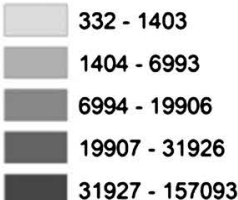

$\stackrel{N}{\Lambda}$

1927 - 157093

Commune's boundaries

Phnom Penh Municapality Office

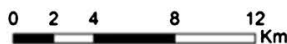

\section{Low Wealth Index (LWI)}

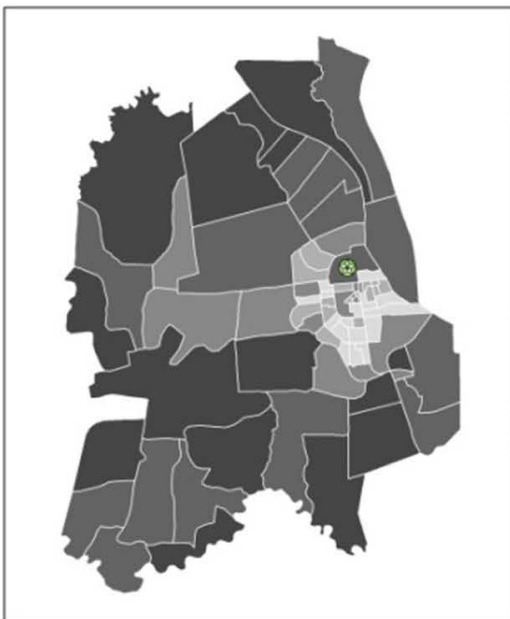

Numbers of household members per residential room

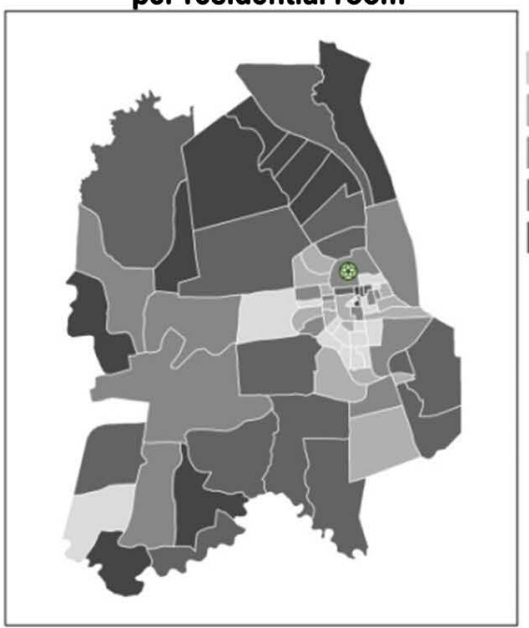

Non-Education Index (NEI)

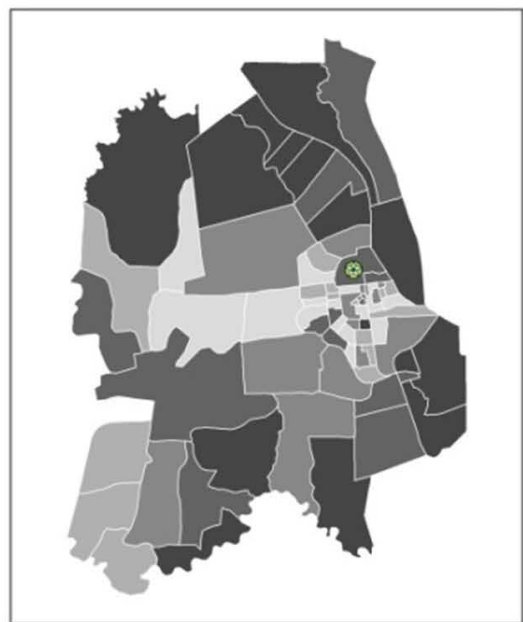

$\%$

Q1 (Richest)

Q2

Q3

Q4

Q5 (Poorest)

$2.35-2.94$

$2.95-3.32$

$3.33-3.52$

$3.53-3.84$

$3.85-4.27$

Figure 2. Population as well as socioeconomic and residential characteristics by communes in Phnom Penh, according to the 2008 General Population Census of Cambodia: LWI was calculated based on six variables of non-ownership of household equipment; NEI was determined as the percentage of population 15 - 64 years old that had never attended school. 
and NEI), and residential characteristics (number of household members per room and percentage living in the same commune $<5$ years). The map of population density showed higher rates in the central areas of the city, while the other maps showed higher parameters in the outlying areas.

For Figure 1 and Figure 2, all cut points for the parameters were quantiles. Table 1 shows average NR of total TB, SPTB, SNTB and extrapulmonary TB by the commune for the 36 months calculated based on the census population. The highest SPTB-NR in a commune was 464 cases per 100,000 population per year.

Table 2 shows the associations between areal rates of SPTB-NR and population density as well as socioeconomic and residential characteristics. Density per room in a household was associated with TB notification rate (PR: $2.80,95 \% \mathrm{CI}$ : 2.68 - 2.93) and the rates were also associated with the TB rates even after adjusting with LWI and NEI (PR with LWI: 1.10, 95\%CI: $1.04-1.17$ and with NEI:

Table 1. Statistics of reported TB cases in 36 months per 100,000 population, Phnom Penh, January 2010-December 2012.

\begin{tabular}{ccccc}
\hline $\begin{array}{c}\text { Notification rate } \\
\text { per 100,000 population }\end{array}$ & Total & Smear-positive & Smear-negative & Extra pulmonary \\
\hline Average notification rate (NR) & 270 & 135 & 68 & 67 \\
Min & 0 & 0 & 0 & 0 \\
Max & 811 & 464 & 386 & 232 \\
Median & 235 & 100 & 42 & 55 \\
\hline
\end{tabular}

Note\#: 159 cases registered in prison (55 SPTB, 88 SNTB and 16 extrapulmonary TB) in Prey Sa were not included in the analysis.

Table 2. Association of commune statistics between smear-positive pulmonary TB notification rate (SPTB-NR) and population density, socioeconomic and residential characteristics, Phnom Penh, January 2010-December 2012, adjusted by socioeconomic characteristics $^{\# \# .}$.

\begin{tabular}{|c|c|c|c|c|c|c|}
\hline & \multicolumn{2}{|c|}{ Crude } & \multicolumn{2}{|c|}{ Adjusted $^{\S}$} & \multicolumn{2}{|c|}{ Adjusted§§ } \\
\hline & PR & $95 \% \mathrm{CI}$ & PR & $95 \% \mathrm{CI}$ & PR & $95 \% \mathrm{CI}$ \\
\hline Population density & $0.99^{* * *}$ & {$[0.99,0.99]$} & $0.99^{* * *}$ & {$[0.99,0.99]$} & $0.99^{* * *}$ & {$[0.99,0.99]$} \\
\hline \multicolumn{7}{|l|}{ Socioeconomic } \\
\hline \multicolumn{7}{|l|}{ Characteristics, commune } \\
\hline Low wealth index (LWI) & $1.97^{* * *}$ & {$[1.93,2.01]$} & & & & \\
\hline Non-education index (NEI) (\%) & $1.05^{\star * *}$ & {$[1.04,1.05]$} & & & & \\
\hline \multirow{2}{*}{\multicolumn{7}{|c|}{$\begin{array}{c}\text { Residential } \\
\text { characteristics, commune }\end{array}$}} \\
\hline & & & & & & \\
\hline $\begin{array}{c}\text { Number of household members } \\
\text { per residential room }\end{array}$ & $2.80^{* * *}$ & {$[2.68,2.93]$} & $1.10^{* *}$ & {$[1.04,1.17]$} & $2.55^{* * *}$ & {$[2.42,2.68]$} \\
\hline $\begin{array}{l}\text { Population living in the same } \\
\text { commune }<5 \text { years }(\%)\end{array}$ & $1.00^{* * *}$ & {$[1.00,1.00]$} & $0.99^{* *}$ & {$[0.99,0.99]$} & $1.00^{* * *}$ & {$[1.00,1.00]$} \\
\hline
\end{tabular}

Note $^{\# \#}$ : All values above were rounded down to two significant figures. CI: confidence interval. ${ }^{\S}$ Adjusted model for Low wealth index (LWI); §§Adjusted model for Non-education index (NEI). ${ }^{\star} P<0.05,{ }^{\star *} P<$ $0.01,{ }^{* * *} P<0.001$. 


\subsection{5, 95\%CI: 2.42 - 2.68).}

Table 3 shows the number and percentage of employed persons by occupation group in Phnom Penh in 2008. Major occupation groups of the employed population in Phnom Penh were service and sales workers and craft and related workers.

Table 4 shows the associations between occupation groups and SPTB-NR by commune. Four of 10 occupation groups were associated with TB rates (PR $>1.00)$.

Table 3. Number and percentage distribution of employed persons by occupation group, Phnom Penh.

\begin{tabular}{ccc}
\hline Occupation Group & Number of employed persons & Percentage of employed persons \\
\hline Armed forces & 15,531 & 2.4 \\
Managers & 11,896 & 1.8 \\
Professionals & 23,532 & 3.6 \\
Clerical support workers & 41,924 & 6.5 \\
Technical associate professionals & 51,660 & 8.0 \\
Services and sales workers & 186,582 & 28.9 \\
Skilled agriculture & 31,886 & 4.9 \\
Craft and related workers & 189,327 & 29.3 \\
Plant machine operators & 39,032 & 6.0 \\
Elementary occupations & 54,500 & 8.4 \\
Total & 645,870 & 100.0 \\
\hline
\end{tabular}

Table 4. Association of commune statistics between smear-positive pulmonary TB notification rate (SPTB-NR) and percentage of population by occupation group, Phnom Penh.

\begin{tabular}{|c|c|c|c|c|c|c|}
\hline \multirow{2}{*}{ Occupation group } & \multicolumn{2}{|c|}{ Crude } & \multicolumn{2}{|c|}{ Adjusted $^{S}$} & \multicolumn{2}{|c|}{ Adjusted $^{\S \S}$} \\
\hline & PR & $95 \% \mathrm{CI}$ & PR & $95 \%$ CI & $\mathrm{PR}$ & $95 \% \mathrm{CI}$ \\
\hline \multicolumn{7}{|l|}{ White-collar } \\
\hline Managers & $0.65^{\star * *}$ & {$[0.64,0.67]$} & $0.89^{* * *}$ & {$[0.87,0.91]$} & $0.68^{* * *}$ & {$[0.66,0.69]$} \\
\hline Professionals & $0.68^{\star * *}$ & {$[0.67,0.69]$} & $0.81^{\star * *}$ & {$[0.80,0.84]$} & $0.66^{\star * \star}$ & {$[0.65,0.67]$} \\
\hline Clerical support workers & $0.88^{* * *}$ & {$[0.87,0.88]$} & $0.93^{* * *}$ & {$[0.92,0.94]$} & $0.88^{* * *}$ & {$[0.88,0.88]$} \\
\hline Technical associate professionals & $0.79^{* * *}$ & {$[0.78,0.79]$} & $0.85^{* * *}$ & {$[0.84,0.86]$} & $0.78^{* * *}$ & {$[0.78,0.79]$} \\
\hline \multicolumn{7}{|l|}{ Blue-collar } \\
\hline Skilled agriculture & $1.02^{\star * *}$ & {$[1.01,1.02]$} & $1.00^{\star * *}$ & {$[1.00,1.00]$} & $1.02^{\star * \star}$ & {$[1.02,1.02]$} \\
\hline Craft and related workers & $1.03^{* * *}$ & {$[1.03,1.03]$} & $1.01^{* * *}$ & {$[1.01,1.01]$} & $1.03^{* * *}$ & {$[1.03,1.04]$} \\
\hline Plant machine operators & $1.09^{* * *}$ & {$[1.08,1.10]$} & $1.04^{* * *}$ & {$[1.03,1.05]$} & $1.04^{* * *}$ & {$[1.03,1.05]$} \\
\hline Elementary occupations & $1.04^{\star * *}$ & {$[1.03,1.04]$} & $0.99^{* * *}$ & {$[0.99,1.00]$} & $1.00^{* * *}$ & {$[1.00,1.00]$} \\
\hline \multicolumn{7}{|l|}{ Others } \\
\hline Armed forces & $0.78^{\star * *}$ & {$[0.77,0.80]$} & $1.13^{* * *}$ & {$[1.11,1.15]$} & $0.84^{\star * *}$ & {$[0.82,0.86]$} \\
\hline Services and sales workers & $0.95^{* * *}$ & {$[0.95,0.96]$} & $0.98^{* * *}$ & {$[0.98,0.98]$} & $0.96^{* * *}$ & {$[0.95,0.96]$} \\
\hline
\end{tabular}

CI: confidence interval. ${ }^{5}$ Adjusted model for Low wealth index (LWI); ${ }^{5 \varsigma}$ Adjusted model for Non-education index (NEI). ${ }^{*} P<0.05,{ }^{* *} P<0.01,{ }^{* *} P<0.001$. 
Having higher room density per household and residency $<5$ years in a commune were associated with TB infection, and these PRs were significant even after adjusting by LWI of non-ownership of typical facilities by a household or by NEI. This phenomenon was also observed in analysis of the following four occupation groups: the skilled agriculture group is the most common occupational group in Cambodia, with $71.28 \%$ of the population belonging to this group; the craft and related workers group consists of garment factory workers; the plant machine operators group includes motodup and tuktuk drivers; and the elementary occupation group includes mining construction workers.

\section{Discussion}

Our commune-based areal analysis of TB with census data revealed a ring-shaped distribution pattern with high SPTB-NR in the outlying areas. In contrast to previous reports, population density was not associated with SPTB-NR in Phnom Penh during the 36-month study period [8] [9] [10]. This was likely to have been due to multifactorial contributing factors, but may also have been partly due to the higher socioeconomic status in the city centre. An unequal distribution of socioeconomic status was seen on the map of LWI (Figure 2).

Poverty is strongly associated with rates of TB infection [11] [12]. The Cambodian education system was severely hindered by the execution of educated people during the period of rule by the Khmer Rouge regime. In addition, the Cambodia Socio-Economic Survey 2010 indicated that children in Cambodia are still forced to give up education to work and supplement the family's income due to poverty. Lower educational status in outlying areas was associated with SPTB-NR.

Living in a house with more people was associated with risk of TB infection. Although the population density was higher in the city centre, higher household density was observed in outlying areas. This suggested higher risk of TB with crowded households, as discussed previously [13] [14]. These results suggest that population density is unlikely to capture the frequency of human-to-human contact and therefore miss the actual risk of TB exposure.

In this study, "mobile population" was defined as a residency $<5$ years in a commune, and therefore could be described as internal migrants. In Cambodia, poverty has been closely associated with migration, with most internal migration being for economic reasons [15]. The mobile population may have been pushed to migrate due to lack of land ownership or lack of economic opportunities at their place of origin. However, internally migrating people are unlikely to own land or property at their destination, and have access only to temporary or seasonal jobs, which allow them only to maintain their status rather than to improve their standard of living. Lack of accessibility to land and resources could be the main drivers of internal migration from the densely populated central areas to the less densely populated outlying areas [16]. The movement of landless people to the outlying areas of the city may contribute further to the spread of 
TB infection to these areas.

Health care workers were reported previously to have increased TB risk [17], and the concept of occupational hazards for such workers is generally accepted. However, the TB risks in other occupational categories have not been monitored. This study revealed associations between certain occupation groups in Cambodia and SPTB-NR. Four occupation groups showing a positive SPTB-NR association have low educational requirements. The NEI map shows the percentage of the population with no education, and this corresponded to the fact that there were more people with those four occupations, especially farmers and garment factory workers, living in outlying areas of the city.

The main strength of this study was the use of data sets from the general population census and the national TB programme. The health data from the TB programme from healthcare centres in each district were centrally gathered and organised, and the data were disaggregated to the commune level before the analysis. One of the limitations of this study is that the study design did not address individuals; however, it allowed us to explore areas and communes with high TB notification rates and enabled us to focus on smaller areas where target populations may reside.

Social protections designed to reduce vulnerability to poverty could support people suffering from incapacities as a result of age, lack of accessibility to education, unemployment and discrimination to secure basic life needs. Although further studies are necessary to determine the precise relationships between internal migration and TB, poverty-driven internal migration should be taken into account to understand the spread of TB infection in outlying areas of the city. Contact tracing may be necessary to determine the spread of TB. Alternatively, educational programmes may encourage high-risk groups to protect themselves from TB infection. Furthermore, internal migration was shown to be associated with occupation groups with high TB risk. Cambodia has been steadily reducing its TB burden due to the rigid implementation of the national TB programme. However, the rate of decline has begun to decrease. As a conclusion, of this study, active surveillance at the level of smaller administrative units may help to increase the rate of decline in TB incidence. Rapid urbanisation changes the environment, and therefore the pattern of TB infections. To address these changes, it is necessary to identify groups that are especially vulnerable to the disease and to implement preventive control measures for these groups.

\section{Acknowledgements}

The authors appreciate Dr. Darapheak Chau, National Institute of Public Health, Cambodia for his support in obtaining national statistics.

\section{Conflicts of Interest}

The authors declare no conflicts of interest regarding the publication of this paper. 


\section{References}

[1] World Health Organization (2015) Use of High Burden Country Lists for TB by WHO in the Post-2015 Era Reference. Geneva.

https://www.who.int/tb/publications/global_report/high_tb_burdencountrylists201 6-2020.pdf

[2] WHO (2015) End TB Strategy. Geneva. http://www.who.int/tb/End_TB_brochure.pdf?ua=1

[3] Vlahov, D., Freudenberg, N., Proietti, F., Ompad, D., Quinn, A., Nandi, V. and Galea, S. (2007) Urban as a Determinant of Health. Journal of Urban Health, 84, 16-26. https://doi.org/10.1007/s11524-007-9169-3

[4] Pareek, M., Greenaway, C., Noori, T., Munoz, J. and Zenner, D. (2016) The Impact of Migration on Tuberculosis Epidemiology and Control in High-Income Countries: A Review. BMC Medicine, 14, 48. https://doi.org/10.1186/s12916-016-0595-5

[5] Hosoglu, S., Tanrikulu, A.C., Dagli, C. and Akalin, S. (2005) Tuberculosis among Health Care Workers in a Short Working Period. American Journal of Infection Control, 33, 23-26. https://doi.org/10.1016/j.ajic.2004.07.013

[6] Alonso-Echanove, J., Granich, R.M., Laszlo, A., Chu, G., Borja, N., Blas, R., Olortegui, A., Binkin, N.J. and Jarvis, W.R. (2001) Occupational Transmission of Mycobacterium Tuberculosis to Health Care Workers in a University Hospital in Lima, Peru. Clinical Infectious Disease, 33, 589-596. https://doi.org/10.1086/321892

[7] WHO (2013) Definitions and Reporting Framework for Tuberculosis. Geneva. http://www.who.int/tb/publications/definitions/en

[8] Shaweno, D., Shaweno, T., Trauer, J., Denholm, J. and McBryde, E.S. (2017) Heterogeneity of Distribution of Tuberculosis in Sheka Zone, Ethiopia: Drivers and Temporal Trends. International Journal of Tuberculosis and Lung Disease, 21, 79-85. https://doi.org/10.5588/ijtld.16.0325

[9] de Abreu, E., Silva, M., Di Lorenzo Oliveira, C., Teixeira Neto, R.G. and Camargos, P.A. (2016) Spatial Distribution of Tuberculosis from 2002 to 2012 in a Midsize City in Brazil. BMC Public Health, 16, 912. https://doi.org/10.1186/s12889-016-3575-y

[10] Munch, Z., Van Lill, S.W.P., Booysen, C.N., Zietsman, H.L., Enarson, D.A. and Beyers, N. (2003) Tuberculosis Transmission Patterns in a High Incidence Area: A Spatial Analysis. International Journal of Tuberculosis and Lung Disease, 7, 271-277.

[11] Wong, M.K., Yadav, R.P., Nishikiori, N. and Eang, M.T. (2013) The Association between Household Poverty Rates and Tuberculosis Case Notification Rates in Cambodia, 2010. Western Pacific Surveillance and Response Journal, 4, 25-33. https://doi.org/10.5365/wpsar.2013.4.1.002

[12] Bhunu, C.P., Mushayabasa, S. and Smith, R.J. (2012) Assessing the Effects of Poverty in Tuberculosis Transmission Dynamics. Applied Mathematical Modelling, 36, 4173-4185. https://doi.org/10.1016/j.apm.2011.11.046

[13] Clark, M., Riben, P. and Nowgesic, E. (2002) The Association of Housing Density, Isolation and Tuberculosis in Canadian First Nations Communities. International Journal of Epidemiology, 31, 940-945. https://doi.org/10.1093/ije/31.5.940

[14] Pelissari, D.M. and Diaz-Quijano, F.A. (2017) Household Crowding as a Potential Mediator of Socioeconomic Determinants of Tuberculosis Incidence in Brazil. PLoS ONE, 12, e0176116. https://doi.org/10.1371/journal.pone.0176116

[15] Guyant, P., Canavati, S.E., Chea, N., Ly, P., Whittaker, M.A., Roca-Feltrer, A. and Yeung, S. (2015) Malaria and the Mobile and Migrant Population in Cambodia: A Population Movement Framework to Inform Strategies for Malaria Control and 
Elimination. Malaria Journal, 14, 252. https://doi.org/10.1186/s12936-015-0773-5

[16] UNESCO, UNDP, IOM and UN-Habitat (2018) The Policy Briefs on Internal Migration in Southeast Asia. Part 2 Country Brief: Cambodia-Overview of Internal Migration in Cambodia.

https://bangkok.unesco.org/sites/default/files/assets/article/Social\%20and\%20Huma $\underline{\mathrm{n} \% 20 \text { Sciences/publications/Brief\%202\%20-\%20Country\%20Brief\%20-\%20Cambodi }}$ a.pdf

[17] Baussano, I., Nunn, P., Williams, B., Pivetta, E., Bugiani, M. and Scano, F. (2011) Tuberculosis among Health Care Workers. Emerging Infectious Disease, 17, 488-494. https://doi.org/10.3201/eid1703.100947 